\title{
Complete genome sequence of the sulfur compounds oxidizing chemolithoautotroph Sulfuricurvum kujiense type strain (YK-1 ${ }^{\mathrm{T}}$ )
}

\author{
Cliff Han ${ }^{1,2}$, Oleg Kotsyurbenko ${ }^{3,4}$, Olga Chertkov ${ }^{1,2}$, Brittany Held ${ }^{1,2}$, Alla Lapidus ${ }^{1}$, Matt \\ Nolan ${ }^{1}$, Susan Lucas ${ }^{1}$, Nancy Hammon ${ }^{1}$, Shweta Deshpande ${ }^{1}$, Jan-Fang Cheng ${ }^{1}$, Roxanne \\ Tapia $^{1,2}$, Lynne Goodwin ${ }^{1,2}$, Sam Pitluck ${ }^{1}$, Konstantinos Liolios ${ }^{1}$, Ioanna Pagani ${ }^{1}$, Natalia \\ Ivanova ${ }^{1}$, Konstantinos Mavromatis ${ }^{1}$, Natalia Mikhailova ${ }^{1}$, Amrita Pati ${ }^{1}$, Amy Chen $^{5}$, Krishna \\ Palaniappan $^{5}$, Miriam Land ${ }^{1,6}$, Loren Hauser ${ }^{1,6}$, Yun-juan Chang ${ }^{1,6}$, Cynthia D. Jeffries ${ }^{1,6}$, \\ Evelyne-Marie Brambilla ${ }^{7}$, Manfred Rohde ${ }^{8}$, Stefan Spring ${ }^{7}$, Johannes Sikorski ${ }^{7}$, Markus \\ Göker $^{7}$, Tanja Woyke ${ }^{1}$, James Bristow ${ }^{1}$, Jonathan A. Eisen ${ }^{1,9}$, Victor Markowitz ${ }^{5}$, Philip \\ Hugenholtz ${ }^{1,10}$, Nikos C. Kyrpides ${ }^{1}$, Hans-Peter Klenk ${ }^{7 *}$, and John C. Detter ${ }^{1,2}$ \\ ${ }^{1}$ DOE Joint Genome Institute, Walnut Creek, California, USA \\ ${ }^{2}$ Los Alamos National Laboratory, Bioscience Division, Los Alamos, New Mexico, USA \\ ${ }^{3}$ Technical University of Braunschweig, Institute for Microbiology, Braunschweig, Germany \\ ${ }^{4}$ Lomonosov Moscow State University, Biological Department, Moscow, Russia \\ ${ }^{5}$ Biological Data Management and Technology Center, Lawrence Berkeley National \\ Laboratory, Berkeley, California, USA \\ ${ }^{6}$ Oak Ridge National Laboratory, Oak Ridge, Tennessee, USA \\ ${ }^{7}$ Leibnitz Institute DSMZ - German Collection of Microorganisms and Cell Cultures, \\ Braunschweig, Germany \\ ${ }^{8} \mathrm{HZI}$ - Helmholtz Centre for Infection Research, Braunschweig, Germany \\ ${ }^{9}$ University of California Davis Genome Center, Davis, California, USA \\ ${ }^{10}$ Australian Centre for Ecogenomics, School of Chemistry and Molecular Biosciences, The \\ University of Queensland, Brisbane, Australia
}

*Corresponding author: Hans-Peter Klenk (hpk@dsmz.de)

Keywords: facultatively anaerobic, microaerobic, motile, Gram-negative, sulfur-oxidizing, mesophilic, chemolithoautotrophic, Helicobacteracea, GEBA

Sulfuricurvum kujiense Kodama and Watanabe 2004 is the type species of the monotypic genus Sulfuricurvum, which belongs to the family Helicobacteraceae in the class Epsilonproteobacteria. The species is of interest because it is frequently found in crude oil and oil sands where it utilizes various reduced sulfur compounds such as elemental sulfur, sulfide and thiosulfate as electron donors. Members of the species do not utilize sugars, organic acids or hydrocarbons as carbon and energy sources. This genome sequence represents the type strain of the only species in the genus Sulfuricurvum. The genome, which consists of a circular chromosome of 2,574,824 bp length and four plasmids of 118,585 bp, 71,513 bp, $51,014 \mathrm{bp}$, and 3,421 bp length, respectively, harboring a total of 2,879 protein-coding and 61 RNA genes and is a part of the Genomic Encyclopedia of Bacteria and Archaea project.

\section{Introduction}

Strain YK-1 ${ }^{\mathrm{T}}$ (= DSM $16994=$ ATCC BAA-921 = JCM 11577 ) is the type strain of the species Sulfuricurvum kujiense, which is the type species of the monotypic genus Sulfuricurvum [1,2]. The genus name was derived from the Latin word 'sulfur' and the Latin word 'curvus' meaning 'curved', yielding the Neo-Latin word 'Sulfuricurvum', the 'curved bacterium that utilizes sulfur' [1]. The species epithet is derived from the Neo-Latin word 'kujiense' (referring to Kuji, Iwate Prefecture,
Japan, where the bacterium was isolated) [1]. Three more strains of the species $S$. kujiense were isolated from the same habitat and exhibited identical physiological characteristics with the type stran YK-1 ${ }^{\mathrm{T}}$ [3]. Sulfuricurvum spp. have been detected in different groundwater environments $[4,5]$ and in oil fields [6]. Here we present a summary classification and a set of features for $S$. kujiense strain YK-1 ${ }^{\mathrm{T}}$, together with the description of the complete genomic sequencing and annotation. 


\section{Classification and features}

A representative genomic 16S rRNA sequence of $S$. kujiense $\mathrm{YK}-1^{\mathrm{T}}$ was compared using NCBI BLAST $[7,8]$ under default settings (e.g., considering only the high-scoring segment pairs (HSPs) from the best 250 hits) with the most recent release of the Greengenes database [9] and the relative frequencies of taxa and keywords, reduced to their stem [10], were determined, weighted by BLAST scores. The most frequently occurring genus was Sulfuricurvum (100.0\%) (3 hits in total). Regarding the three hits to sequences from members of the species, the average identity within HSPs was 99.1\%, whereas the average coverage by HSPs was $92.9 \%$. No hits to sequences with (other) species names were found. (Note that the Greengenes database uses the INSDC (= EMBL/NCBI/DDBJ) annotation, which is not an authoritative source for nomenclature or classification.)
The highest-scoring environmental sequence was AB030609 ('groundwater clone 1061') [11], which showed an identity of $99.7 \%$ and an HSP coverage of $96.9 \%$. The most frequently occurring keywords within the labels of all environmental samples which yielded hits were 'spring' (9.6\%), 'cave' (9.4\%), 'microbi' (6.9\%), 'sulfid' (5.7\%) and 'mat' (5.2\%) (247 hits in total). These keywords suggest that habitats for S. kujiense well-matched to that supposed in the original description [1] and other publications [3,12]. Environmental samples which yielded hits of a higher score than the highest scoring species were not found.

Figure 1 shows the phylogenetic neighborhood of S. kujiense $\mathrm{YK}-1^{\mathrm{T}}$ in a $16 \mathrm{~S}$ rRNA based tree. The sequences of the three $16 \mathrm{~S}$ rRNA gene copies in the genome differ from each other by one nucleotide, and differ by up to two nucleotides from the previously published $16 \mathrm{~S}$ rRNA sequence (AB053951).

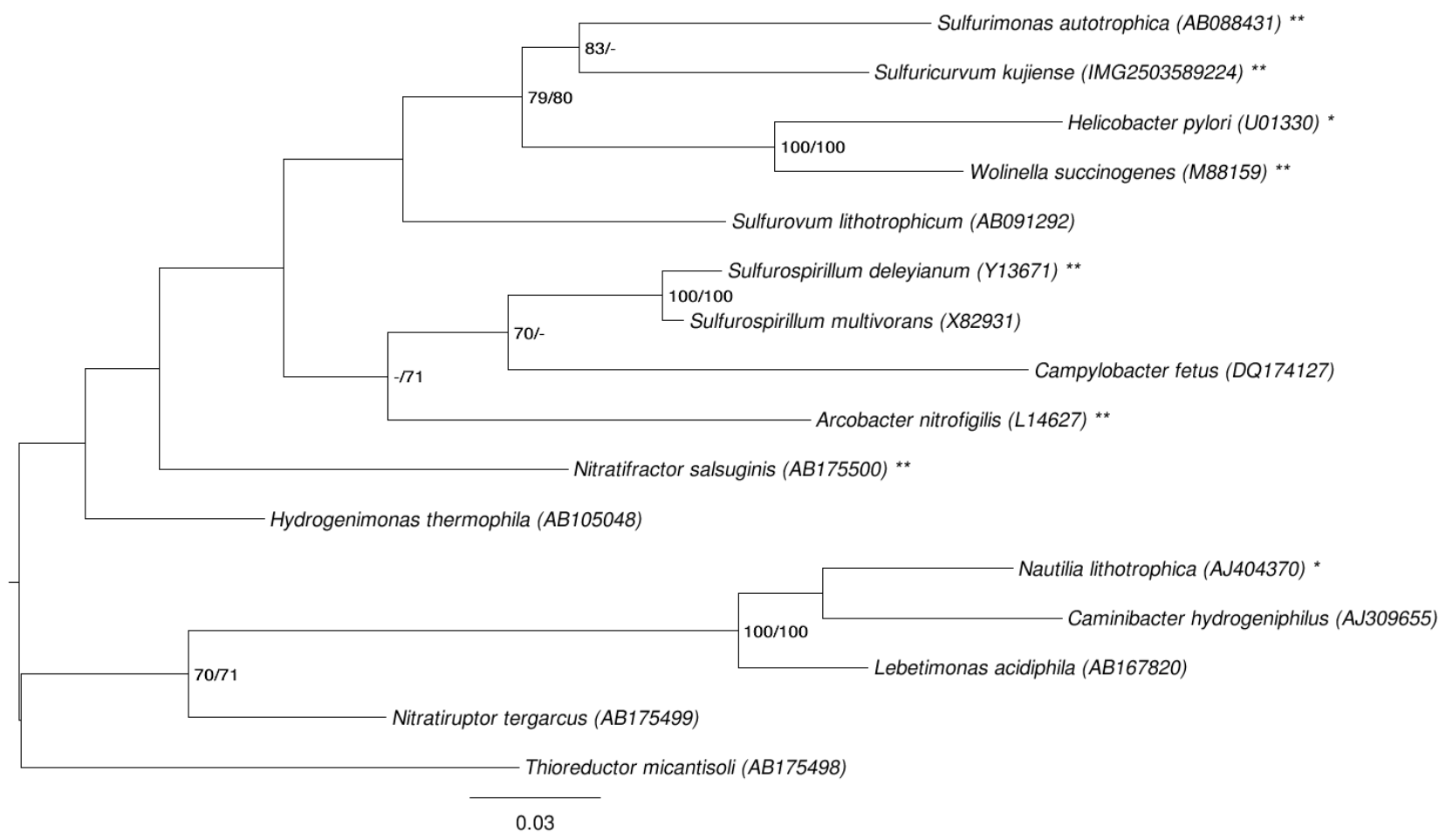

Figure 1. Phylogenetic tree highlighting the position of $S$. kujiense relative to the type strains of the type species of the other genera within the class Epsilonproteobacteria. The tree was inferred from 1,364 aligned characters $[13,14]$ of the $16 \mathrm{~S}$ rRNA gene sequence under the maximum likelihood (ML) criterion [15]. Rooting was done initially using the midpoint method [16] and then checked for its agreement with the current classification (Table 1). The branches are scaled in terms of the expected number of substitutions per site. Numbers adjacent to the branches are support values from 1,000 ML bootstrap replicates [17] (left) and from 1,000 Maximum-Parsimony bootstrap replicates [18] (right) if larger than $60 \%$. Lineages with type strain genome sequencing projects registered in GOLD [19] are labeled with one asterisk, those also listed as 'Complete and Published' with two asterisks [20-24]. 
As one of the families selected for Figure 1, Nautiliaceae (comprising the genera Caminibacter, Lebetimonas, Nautilia, Nitratifractor, Nitratiruptor and Thioreductor) did not appear as monophyletic in the tree, we conducted both unconstrained heuristic searches for the best tree under the maximum likelihood (ML) [15] and maximum parsimony (MP) criteria [18] as well as searches constrained for the monophyly of all families (for details of the data matrix see the figure caption). Our own re-implementation of CopyCat [25] in conjunction with AxPcoords and AxParafit [26] was used to determine those leaves (species) whose placement significantly deviated between the constrained and the unconstrained tree. The bestknown ML tree had a log likelihood of $-8,012.83$, whereas the best trees found under the constraint had a log likelihood of $-8,014.70$. The significantly $(\alpha=0.05)$ distinctly placed species were Hydrogenimonas thermophila ('Hydrogenimonaceae), Nitratifractor salsuginis and Thioreductor micantisoli (Nautiliaceae). However, the constrained tree was not significantly worse than the globally best one in the Shimodaira-Hasegawa test as implemented in RAxML [15] $(\alpha=0.05)$. The best-known MP trees had a score of 1,290 , whereas the best constrained trees found had a score of 1,295 and were not significantly worse in the Kishino-Hasegawa test as implemented in PAUP* [16] $(\alpha=0.05)$. (See, e.g. chapter 21 in [27] for an in-depth description of such paired-site tests.) Accordingly, the current classification of Campylobacterales (Campylobacteraceae, Helicobacteraceae, 'Hydrogenimonaceae'] and
Nautiliales (Nautiliaceae) is not in significant disagreement with the $16 \mathrm{~S}$ rRNA data.

The cells of strain YK-1 $1^{\mathrm{T}}$ are curved rods of $0.4 \times$ 1-2 $\mu \mathrm{m}$ length (Figure 2) [1]. Spiral cells are also observed in the exponential growth phase [1]. $S$. kujiense cells stain Gram-negative and non sporeforming (Table 1). The organism is described as motile with one polar flagellum (not visible in Figure 2). Motility-related genes account for $5.3 \%$ of total genes in the genome (COG category $\mathrm{N}$ ). The organism is a facultatively anaerobic chemolithoautotroph [1,3]. S. kujiense can grow only under $\mathrm{NaCl}$ concentrations below 1\% [1,3]. A lowion-strength medium (MBM) has been developed for growing $S$. kujiense [1,3]. The organism also grows in solid medium containing $1.5 \%$ Bactoagar $[1,3]$. The temperature range for growth is between $10^{\circ} \mathrm{C}$ and $35^{\circ} \mathrm{C}$, with an optimum at $25^{\circ} \mathrm{C}$ $[1,3]$. The $\mathrm{pH}$ range for growth is $6.0-8.0$, with an optimum at $\mathrm{pH} 7.0 \quad[1,3]$. S. kujiense grows autotrophically on carbon dioxide and bicarbonate $[1,3]$. The organism does not utilize organic acids such as acetate, lactate, pyruvate, malate, succinate, or formate nor does it utilize methanol, glucose or glutamate $[1,3]$. S. kujiense is not able to ferment phenol, octane, toluene, benzene, benzoate or ascorbate $[1,3]$. S. kujiense uses sulfide, elemental sulfur, thiosulfate and hydrogen as electron donors, and nitrate as well as small amounts of molecular oxygen (1\% in gas phase) as electron acceptors $[1,3]$. It does not utilize nitrite $[1,3]$. $S$. kujiense shows oxidase activity, but is catalasenegative $[1,3]$. The organism is of ecological interest because of its ability to utilize different sulfur species and nitrate $[1,3]$.

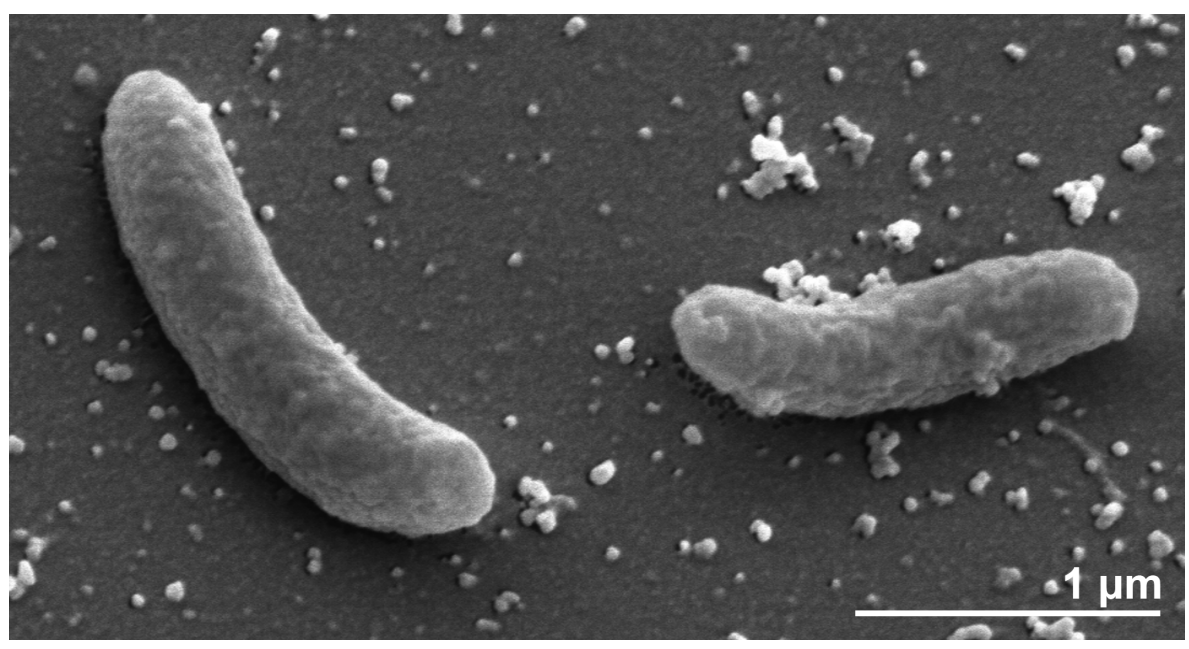

Figure 2. Scanning electron micrograph of S. kujiense $\mathrm{YK}-1^{\top}$ 
Han et al.

Table 1. Classification and general features of $S$. kujiense $Y K-1^{\top}$ according to the MIGS recommendations [28] and the NamesforLife database [29].

\begin{tabular}{|c|c|c|c|}
\hline MIGS ID & Property & Term & Evidence code \\
\hline & \multirow{8}{*}{ Current classification } & Domain Bacteria & TAS [30] \\
\hline & & Phylum Proteobacteria & $\overline{\text { TAS [31] }}$ \\
\hline & & Class Epsilonproteobacteria & TAS [32,33] \\
\hline & & Order Campylobacterales & $\underline{\text { TAS }[32,34]}$ \\
\hline & & Family Helicobacteraceae & TAS [32,35] \\
\hline & & Genus Sulfuricurvum & $\underline{\text { TAS [1] }}$ \\
\hline & & Species Sulfuricurvum kujiense & TAS [1] \\
\hline & & Type strain YK-1 & TAS [1] \\
\hline & Gram stain & negative & TAS [1] \\
\hline & Cell shape & curved rods & TAS [1] \\
\hline & Motility & motile & TAS [1] \\
\hline & Sporulation & none & $\underline{\text { TAS [1] }}$ \\
\hline & Temperature range & $10^{\circ} \mathrm{C}-35^{\circ} \mathrm{C}$ & TAS [1] \\
\hline & Optimum temperature & $25^{\circ} \mathrm{C}$ & TAS [1] \\
\hline & Salinity & below $1 \% \mathrm{NaCl}$; best without $\mathrm{NaCl}$ & TAS [1] \\
\hline \multirow[t]{3}{*}{ MIGS-22 } & Oxygen requirement & anaerobic, microaerobic & TAS [1] \\
\hline & Carbon source & carbon dioxide, bicarbonate & $\underline{\text { TAS [1] }}$ \\
\hline & Energy metabolism & chemolithoautotroph & $\overline{\text { TAS [1] }}$ \\
\hline MIGS-6 & Habitat & groundwater & $\overline{\text { TAS }[3,11]}$ \\
\hline MIGS-15 & Biotic relationship & free-living & NAS \\
\hline \multirow[t]{3}{*}{ MIGS-14 } & Pathogenicity & none & NAS \\
\hline & Biosafety level & 1 & TAS [36] \\
\hline & Isolation & $\begin{array}{l}\text { drain water from an underground crude-oil } \\
\text { storage cavity }\end{array}$ & TAS $[3,11]$ \\
\hline MIGS-4 & Geographic location & Kuji in Iwate, Japan & TAS [1] \\
\hline MIGS-5 & Sample collection time & March 1999 & TAS $[3,11]$ \\
\hline MIGS-4.1 & Latitude & 40.19 & NAS \\
\hline MIGS-4.2 & Longitude & 141.78 & NAS \\
\hline MIGS-4.3 & Depth & not reported & \\
\hline MIGS-4.4 & Altitude & sea level & NAS \\
\hline
\end{tabular}

Evidence codes - NAS: Non-traceable Author Statement (i.e., not directly observed for the living, isolated sample, but based on a generally accepted property for the species, or anecdotal evidence). These evidence codes are from the Gene Ontology project [37].

\section{Genome sequencing and annotation \\ Genome project history}

This organism was selected for sequencing on the basis of its phylogenetic position [38], and is part of the Genomic Encyclopedia of Bacteria and Archaea project [39]. The genome project is deposited in the Genomes On Line Database [19] and the complete genome sequence is deposited in GenBank. Sequencing, finishing and annotation were performed by the DOE Joint Genome Institute (JGI). A summary of the project information is shown in Table 2.

\section{Growth conditions and DNA isolation}

S. kujiense strain YK-1T, DSM 16994, was grown anaerobically in DSMZ medium 1020 (MBM medium) [40] at $25^{\circ} \mathrm{C}$. DNA was isolated from $0.5-1 \mathrm{~g}$ of cell paste using MasterPure Gram-positive DNA purification kit (Epicentre MGP04100) following the standard protocol as recommended by the manufacturer with modification st/DL for cell lysis as described in Wu et al. 2009 [39]. DNA is available through the DNA Bank Network [41]. 


\begin{tabular}{lll}
\hline Table 2. Genome sequencing project information \\
\hline MIGS ID & Property & Term \\
MIGS-31 & Finishing quality & Finished \\
MIGS-28 & Libraries used & Three genomic libraries: one 454 pyrosequence standard library, one \\
MIGS-29 & Sequencing platforms & 454 PE library (8.7 kb insert size), one Illumina library \\
MIGS-31.2 & Sequencing coverage & Illuma GAii, 454 GS FLX Titanium \\
MIGS-30 & Assemblers & Newbler version $2.31 .1 \times$ pyrosequence \\
MIGS-32 & Gene calling method & Prodigal 1.4, GenePRIMP version SPS - 4.24 \\
& INSDC ID & CP002355 (chromosome) \\
& Genbank Date of Release & CP002356-9 (plasmids SULKU01-04) \\
& October 7, 2011 (chromosome and plasmids) \\
& NCBI project ID & Gc01552 \\
& Database: IMG-GEBA & 43399 \\
& Source material identifier & DSM 16994 \\
& Project relevance & Tree of Life, GEBA \\
\hline
\end{tabular}

\section{Genome sequencing and assembly}

The genome was sequenced using a combination of Illumina and 454 sequencing platforms. All general aspects of library construction and sequencing can be found at the JGI website [42]. Pyrosequencing reads were assembled using the Newbler assembler (Roche). The initial Newbler assembly consisting of 18 contigs in two scaffolds was converted into a phrap [43] assembly by making fake reads from the consensus, to collect the read pairs in the 454 paired end library. Illumina GAii sequencing data (788.0 Mb) was assembled with Velvet [44] and the consensus sequences were shredded into $1.5 \mathrm{~kb}$ overlapped fake reads and assembled together with the 454 data. The 454 draft assembly was based on $124.3 \mathrm{Mb} 454 \mathrm{draft}$ data and all of the 454 paired end data. Newbler parameters are $\begin{array}{llllllllll}\text { consed } & -\mathrm{a} & 50 & -\mathrm{l} & 350 & -\mathrm{g} & -\mathrm{m} & -\mathrm{ml} & 20 . & \text { The }\end{array}$ Phred/Phrap/Consed software package [43] was used for sequence assembly and quality assessment in the subsequent finishing process. After the shotgun stage, reads were assembled with parallel phrap (High Performance Software, LLC). Possible mis-assemblies were corrected with gapResolution [43], Dupfinisher [45], or sequencing cloned bridging PCR fragments with subcloning. Gaps between contigs were closed by editing in Consed, by PCR and by Bubble PCR primer walks (J.-F. Chang, unpublished). A total of 85 additional reactions were necessary to close gaps and to raise the quality of the finished sequence. Illumina reads were also used to correct potential base errors and increase consensus quality using a software Polisher developed at JGI [46]. The error rate of the completed genome sequence is less than 1 in 100,000. Together, the combination of the Illumina and 454 sequencing platforms provided $408.5 \times$ coverage of the genome. The final assembly contained 368,924 pyrosequence and $27,990,437$ Illumina reads.

\section{Genome annotation}

Genes were identified using Prodigal [47] as part of the Oak Ridge National Laboratory genome annotation pipeline, followed by a round of manual curation using the JGI GenePRIMP pipeline [48]. The predicted CDSs were translated and used to search the National Center for Biotechnology Information (NCBI) nonredundant database, UniProt, TIGR-Fam, Pfam, PRIAM, KEGG, COG, and InterPro databases. Additional gene prediction analysis and functional annotation was performed within the Integrated Microbial Genomes - Expert Review (IMG-ER) platform [49].

\section{Genome properties}

The genome consists of a 2,574,824 bp long circular chromosome with a $\mathrm{G}+\mathrm{C}$ content of $45 \%$ and four circular plasmids of 3,421 bp, 51,014 bp, $71,513 \mathrm{bp}$ and 118,585 bp length, respectively (Table 3 and Figure 3). Of the 2,879 genes predicted, 2,818 were protein-coding genes, and 61 RNAs; 20 pseudogenes were also identified. The majority of the protein-coding genes $(67.9 \%)$ were assigned with a putative function while the remaining ones were annotated as hypothetical proteins. The distribution of genes into COGs functional categories is presented in Table 4. 
Table 3. Genome Statistics

\begin{tabular}{lrr}
\hline Attribute & Value & \% of Total \\
\hline Genome size (bp) & $2,819,357$ & $100.00 \%$ \\
DNA coding region (bp) & $2,623,121$ & $93.04 \%$ \\
DNA G+C content (bp) & $1,256,420$ & $44.56 \%$ \\
Number of replicons & 5 & $100 \%$ \\
Extrachromosomal elements & 4 & \\
Total genes & 2,879 & $100.00 \%$ \\
RNA genes & 61 & $2.12 \%$ \\
rRNA operons & 3 & \\
Protein-coding genes & 2,818 & $97.88 \%$ \\
Pseudo genes & 20 & $0.69 \%$ \\
Genes with function prediction & 1,964 & $67.87 \%$ \\
Genes in paralog clusters & 1,264 & $43.90 \%$ \\
Genes assigned to COGs & 2,129 & $73.95 \%$ \\
Genes assigned Pfam domains & 2,100 & $72.94 \%$ \\
Genes with signal peptides & 926 & $32.16 \%$ \\
Genes with transmembrane helices & 633 & $21.99 \%$ \\
CRISPR repeats & 0 & \\
\hline
\end{tabular}

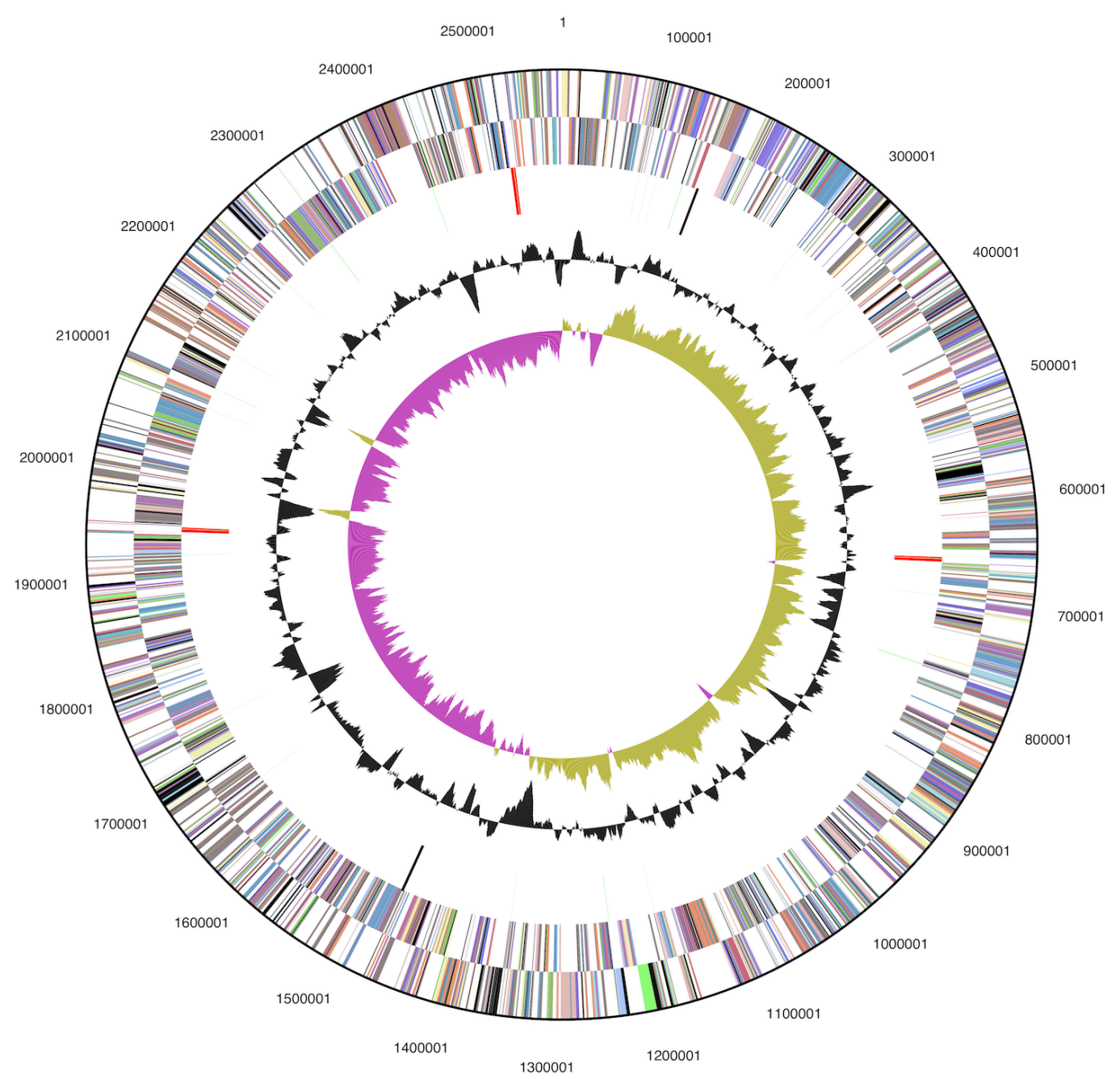

Figure 3. Graphical map of the chromosome (plasmids not shown). From bottom to center: Genes on forward strand (color by COG categories), Genes on reverse strand (color by COG categories), RNA genes (tRNAs green, rRNAs red, other RNAs black), GC content, GC skew. 
Table 4. Number of genes associated with the general COG functional categories

\begin{tabular}{crrl}
\hline Code & Value & \%age & Description \\
\hline J & 154 & 6.4 & Translation, ribosomal structure and biogenesis \\
A & 0 & 0.0 & RNA processing and modification \\
K & 119 & 5.0 & Transcription \\
L & 126 & 5.3 & Replication, recombination and repair \\
B & 0 & 0.0 & Chromatin structure and dynamics \\
D & 33 & 1.4 & Cell cycle control, cell division, chromosome partitioning \\
Y & 0 & 0.0 & Nuclear structure \\
V & 46 & 1.9 & Defense mechanisms \\
T & 283 & 11.8 & Signal transduction mechanisms \\
M & 177 & 7.4 & Cell wall/membrane/envelope biogenesis \\
N & 127 & 5.3 & Cell motility \\
Z & 0 & 0.0 & Cytoskeleton \\
W & 0 & 0.0 & Extracellular structures \\
U & 96 & 4.0 & Intracellular trafficking, secretion, and vesicular transport \\
O & 102 & 4.3 & Posttranslational modification, protein turnover, chaperones \\
C & 168 & 7.0 & Energy production and conversion \\
G & 73 & 3.1 & Carbohydrate transport and metabolism \\
E & 129 & 5.4 & Amino acid transport and metabolism \\
F & 57 & 2.4 & Nucleotide transport and metabolism \\
H & 107 & 4.5 & Coenzyme transport and metabolism \\
I & 40 & 1.7 & Lipid transport and metabolism \\
P & 134 & 5.6 & Inorganic ion transport and metabolism \\
Q & 21 & 0.9 & Secondary metabolites biosynthesis, transport and catabolism \\
R & 229 & 9.6 & General function prediction only \\
\hline & 175 & 7.3 & Function unknown \\
\hline
\end{tabular}

\section{Acknowledgements}

We would like to gratefully acknowledge the help of Maren Schröder (DSMZ) for growing S. kujiense cultures. This work was performed under the auspices of the US Department of Energy Office of Science, Biological and Environmental Research Program, and by the University of California, Lawrence Berkeley National Laboratory under contract No. DE-AC02-05CH11231,
Lawrence Livermore National Laboratory under Contract No. DE-AC52-07NA27344, and Los Alamos National Laboratory under contract No. DE-AC0206NA25396, UT-Battelle and Oak Ridge National Laboratory under contract DE-AC05-000R22725, as well as German Research Foundation (DFG) INST 599/1-2. 


\section{References}

1. Kodama Y, Watanabe K. Sulfuricurvum kujiense gen.nov., sp. nov., a facultatively anaerobic, chemolithoautotrophic, sulfur-oxidizing bacterium isolated from an underground crude-oil storage cavity. Int I Syst Evol Microbiol 2004;

54:2297-2300. PubMed http://dx.doi.org/10.1099/ijs.0.63243-0

2. Euzeby J. List of bacterial names with standing in nomenclature: A folder available on the Internet. Int J Syst Bacteriol 1997; 47:590-592. PubMed http://dx.doi.org/10.1099/00207713-47-2-590

3. Kodama Y, Watanabe K. Isolation and characterization of a sulfur-oxidizing chemolithotroph growing on crude oil under anaerobic conditions. Appl Environ Microbiol 2003; 69:107-112. PubMed http://dx.doi.org/10.1128/AEM.69.1.107$\underline{112.2003}$

4. Campbell BJ, Engel AS, Porter ML, Takai K. The versatile $\varepsilon$-proteobacteria: key players in sulphidic habitats. Nat Rev Microbiol 2006; 4:458-468. PubMed http://dx.doi.org/10.1038/nrmicro1414

5. Porter ML, Engel AS. Diversity of uncultured Epsilonproteobacteria from terrestrial sulfidic caves and springs. Appl Environ Microbiol 2008; 74:4973-4977. PubMed http://dx.doi.org/10.1128/AEM.02915-07

6. Hubert CR, Oldenburg TBP, Fustic M, Gray ND, Larter SR, Penn K, Rowan AK, Seshadri R, Sherry A, Swainsbury R, et al. Massive dominance of Epsilonproteobacteria in formation waters from a Canadian oil sands reservoir containing severely biodegraded oil. [PubMed]. Environ Microbiol 2011; (In press). PubMed

7. Altschul SF, Gish W, Miller W, Myers E, Lipman D. Basic local alignment search tool. [PubMed]. J Mol Biol 1990; 215:403-410. PubMed

8. Korf I, Yandell M, Bedell J. BLAST, O'Reilly, Sebastopol, 2003.

9. DeSantis TZ, Hugenholtz $\mathrm{P}$, Larsen N, Rojas $\mathrm{M}$, Brodie EL, Keller K, Huber T, Dalevi D, Hu P, Andersen GL. Greengenes, a chimera-checked $16 \mathrm{~S}$ rRNA gene database and workbench compatible with ARB. Appl Environ Microbiol 2006; 72:5069-5072. PubMed http://dx.doi.org/10.1128/AEM.03006-05

10. Porter MF. An algorithm for suffix stripping. Program: electronic library and information systems 1980; 14:130-137.

11. Watanabe K, Watanabe K, Kodama Y, Syutsubo K, Harayama S. Molecular characterization of bacterial populations in petroleum-contaminated groundwater discharged from underground crude oil storage cavities. Appl Environ Microbiol 2000; 66:4803-4809. PubMed http://dx.doi.org/10.1128/AEM.66.11.4803$\underline{4809.2000}$

12. Haaijer SC, Harhangi HR, Meijerink BB, Strous M, Pol A, Smolders AJ, Verwegen K, Jetten MS, Op den Camp HJ. Bacteria associated with iron seeps in a sulfur-rich, neutral $\mathrm{pH}$, freshwater ecosystem. ISME J 2008; 2:1231-1242. PubMed http://dx.doi.org/10.1038/ismej.2008.75

13. Lee C, Grasso C, Sharlow MF. Multiple sequence alignment using partial order graphs. BioinformatiCs 2002; 18:452-464. PubMed http://dx.doi.org/10.1093/bioinformatics/18.3.452

14. Castresana J. Selection of conserved blocks from multiple alignments for their use in phylogenetic analysis. [PubMed]. Mol Biol Evol 2000; 17:540552. PubMed

15. Stamatakis A, Hoover P, Rougemont J. A rapid bootstrap algorithm for the RAxML web-servers. Syst Biol 2008; 57:758-771. PubMed http://dx.doi.org/10.1080/10635150802429642

16. Hess PN, De Moraes Russo CA. An empirical test of the midpoint rooting method. Biol / Linn SoC Lond 2007; 92:669-674. http://dx.doi.org/10.1111/j.1095$\underline{\text { 8312.2007.00864.x }}$

17. Pattengale ND, Alipour $M$, Bininda-Emonds ORP, Moret BME, Stamatakis A. How many bootstrap replicates are necessary? Lect Notes Comput Sci 2009; 5541:184-200. http://dx.doi.org/10.1007/978-3-642-02008-7_13

18. Swofford DL. PAUP*: Phylogenetic Analysis Using Parsimony (*and Other Methods), Version 4.0 b10. Sinauer Associates, Sunderland, 2002.

19. Liolios K, Chen IM, Mavromatis K, Tavernarakis $\mathrm{N}$, Hugenholtz P, Markowitz VM, Kyrpides NC. The Genomes On Line Database (GOLD) in 2009: status of genomic and metagenomic projects and their associated metadata. Nucleic Acids Res 2010; 38:D346-D354. PubMed http://dx.doi.org/10.1093/nar/gkp848

20. Sikorski J, Munk C, Lapidus A, Ngatchou Djao OD, Lucas S, Glavina Del Rio T, Nolan M, Tice $\mathrm{H}$, Han C, Cheng JF, et al. Complete genome sequences of Sulfurimonas autotrophica type strain (OK 10T). Stand Genomic Sci 2010; 3:194-202. PubMed 
21. Baar C, Eppinger M, Raddatz G, Simon J, Lanz C, Klimmek O, Nandakumar R, Gross R, Rosinus A, Keller $\mathrm{H}$, et al. Complete genome sequence and analysis of Wolinella succinogenes. Proc Natl Acad Sci USA 2003; 100:11690-11695. PubMed http://dx.doi.org/10.1073/pnas.1932838100

22. Sikorski J, Lapidus A, Copeland A, Glavina Del Rio T, Nolan M, Lucas S, Chen F, Tice H, Cheng JF, Saunders E, et al. Complete genome sequence of Sulfurospirillum deleyianum type strain $\left(5175^{\top}\right)$. Stand Genomic Sci 2010; 2:149-157. PubMed http://dx.doi.org/10.4056/sigs.671209

23. Pati A, Gronow S, Lapidus A, Copeland A, Glavina Del Rio T, Nolan M, Lucas S, Tice H, Cheng JF, Han C, et al. Complete genome sequence of Arcobacter nitrofigilis type strain $\left(\mathrm{Cl}^{\top}\right)$. Stand Genomic Sci 2010; 2:300-308. PubMed http://dx.doi.org/10.4056/sigs.912121

24. Anderson I, Sikorski J, Zeytun A, Nolan M, Lapidus A, Lucas S, Hammon N, Deshpande S, Cheng JF, Tapia R, et al. Complete genome sequence of Nitratifractor salsuginis type strain $\left(\right.$ E9I37-1 ${ }^{\mathrm{T}}$ ). Stand Genomic Sci 2011; 4:322-330. PubMed http://dx.doi.org/10.4056/sigs.1844518

25. Meier-Kolthoff JP, Auch AF, Huson DH, Göker M. COPYCAT: Co-phylogenetic Analysis tool. Bioinformatics 2007; 23:898-900. PubMed http://dx.doi.org/10.1093/bioinformatics/btm027

26. Stamatakis A, Auch A, Meier-Kolthoff JP, Göker M. AxPcoords \& Parallel AxParafit: Statistical cophylogenetic analyses on thousands of taxa. BMC Bioinformatics 2007; 8:405. PubMed http://dx.doi.org/10.1186/1471-2105-8-405

27. Felsenstein J. Inferring phylogenies. Sinauer Associates Inc., Sunderland, Massachusetts, 2004.

28. Field D, Garrity G, Gray T, Morrison N, Selengut J, Sterk P, Tatusova T, Thomson N, Allen MJ, Angiuoli SV, et al. The minimum information about a genome sequence (MIGS) specification. Nat Biotechnol 2008; 26:541-547. PubMed http://dx.doi.org/10.1038/nbt1360

29. Garrity G. NamesforLife. BrowserTool takes expertise out of the database and puts it right in the browser. Microbiol Today 2010; 37:9.

30. Woese CR, Kandler O, Wheelis ML. Towards a natural system of organisms: proposal for the domains Archaea, Bacteria, and Eucarya. Proc Natl Acad Sci USA 1990; 87:4576-4579. PubMed http://dx.doi.org/10.1073/pnas.87.12.4576

31. Garrity GM, Bell JA, Lilburn T. Phylum XIV. Proteobacteria phyl. nov. In: Garrity GM, Brenner
DJ, Krieg NR, Staley JT (eds), Bergey's Manual of Systematic Bacteriology, Second Edition, Volume 2, Part B, Springer, New York, 2005, p. 1.

32. Validation List No. 107. List of new names and new combinations previously effectively, but not validly, published. [PubMed]. Int / Syst Evol Microbiol 2006; 56:1-6. PubMed http://dx.doi.org/10.1099/ijs.0.64188-0

33. Garrity GM, Bell JA, Lilburn T. Class V. Epsilonproteobacteria class. nov. In: Garrity GM, Brenner DJ, Krieg NR, Staley JT (eds), Bergey's Manual of Systematic Bacteriology, Second Edition, Volume 2, Part C, Springer, New York, 2005, p. 1145.

34. Garrity GM, Bell JA, Lilburn T. Order I. Campylobacterales ord. nov. In: Garrity GM, Brenner DJ, Krieg NR, Staley JT (eds), Bergey's Manual of Systematic Bacteriology, Second Edition, Volume 2, Part C, Springer, New York, 2005, p. 1145.

35. Garrity GM, Bell JA, Lilburn T. Family II. Helicobacteraceae fam. nov. In: Garrity GM, Brenner DJ, Krieg NR, Staley JT (eds), Bergey's Manual of Systematic Bacteriology, Second Edition, Volume 2, Part C, Springer, New York, 2005, p. 1168.

36. BAuA. Classification of bacteria and archaea in risk groups. TRBA 466. p. 227. Bundesanstalt für Arbeitsschutz und Arbeitsmedizin, Germany. 2010.

37. Ashburner M, Ball CA, Blake JA, Botstein D, Butler H, Cherry JM, Davis AP, Dolinski K, Dwight SS, Eppig JT, et al. Gene Ontology: tool for the unification of biology. Nat Genet 2000; 25:25-29. PubMed http://dx.doi.org/10.1038/75556

38. Klenk HP, Göker M. En route to a genome-based classification of Archaea and Bacteria? Syst Appl Microbiol 2010; 33:175-182. PubMed http://dx.doi.org/10.1016/j.syapm.2010.03.003

39. Wu D, Hugenholtz P, Mavromatis K, Pukall R, Dalin E, Ivanova NN, Kunin V, Goodwin L, Wu $M$, Tindall BJ, et al. A phylogeny-driven genomic encyclopaedia of Bacteria and Archaea. Nature 2009; 462:1056-1060. PubMed http://dx.doi.org/10.1038/nature08656

40. List of growth media used at DSMZ: http//www.dsmz.de/catalogues/cataloguemicroorganisms/culture-technology/list-of-mediafor-microorganisms.html.

41. Gemeinholzer B, Dröge G, Zetzsche $H$, Haszprunar G, Klenk HP, Güntsch A, Berendsohn 
WG, Wägele JW. The DNA Bank Network: the start from a German initiative. Biopreserv Biobank 2011; 9:51-55.

http://dx.doi.org/10.1089/bio.2010.0029

42. JGI website. http://www.jgi.doe.gov/.

43. The Phred/Phrap/Consed software package. http://www.phrap.com.

44. Zerbino DR, Birney E. Velvet: algorithms for de novo short read assembly using de Bruijn graphs. Genome Res 2008; 18:821-829. PubMed http://dx.doi.org/10.1101/gr.074492.107

45. Han C, Chain P. Finishing repeat regions automatically with Dupfinisher. In: Proceeding of the 2006 international conference on bioinformatics \& computational biology. Arabnia HR, Valafar $\mathrm{H}$ (eds), CSREA Press. June 26-29, 2006: 141-146.

46. Lapidus A, LaButti K, Foster B, Lowry S, Trong S, Goltsman E. POLISHER: An effective tool for us- ing ultra short reads in microbial genome assembly and finishing. AGBT, Marco Island, FL, 2008.

47. Hyatt $\mathrm{D}$, Chen GL, LoCascio PF, Land ML, Larimer FW, Hauser LJ. Prodigal: prokaryotic gene recognition and translation initiation site identification. BMC Bioinformatics 2010; 11:119. PubMed http://dx.doi.org/10.1186/1471-2105-11-119

48. Pati A, Ivanova NN, Mikhailova N, Ovchinnikova G, Hooper SD, Lykidis A, Kyrpides NC.

GenePRIMP: a gene prediction improvement pipeline for prokaryotic genomes. Nat Methods 2010; 7:455-457. PubMed http://dx.doi.org/10.1038/nmeth.1457

49. Markowitz VM, Ivanova NN, Chen IMA, Chu K, Kyrpides NC. IMG ER: a system for microbial genome annotation expert review and curation. Bioinformatics 2009; 25:2271-2278. PubMed http://dx.doi.org/10.1093/bioinformatics/btp393 